\title{
The Meteorological Disasters Risk Analysis and Risk Management in Large Scale Activities
}

\author{
Haibo $\mathrm{Hu}^{1}$ Yanli Zhang ${ }^{2}$ \\ ${ }^{1}$ Institute of Urban Meteorology, CMA, Beijing 100089, China \\ ${ }^{2}$ Beijing Meteorological Bureau, Beijing 100089, China
}

\begin{abstract}
On the basis of risk analysis, the risk control and risk sustainability should be assessed for the requirement of risk management on the meteorological disaster so that it can keep safeties during large-scale activities. Thus, the AHP model combined with the method of experts score is introduced in the assessment of risk control and risk sustainability, and then the risk index can be corrected accordingly to reflect the real risk status, and be used for risk ranking and sorting. Our research takes the case study of meteorological disasters risk assessment during the celebration days on the victory of anti-Japanese war. The high impact weathers of rainfall, haze, thunderstorm, fog and high temperature are recognized as the risk sources. After the risk analysis as well as the assessment on risk control and risk sustainability, these conclusions can be drawn as the followings. The possibility of rainfall is relatively high during the period of celebration days, additional to weak risk control and sustainability to rainfall, the risk induced by precipitation could be high during that days. Though the possibility of haze can be high, the good risk control and sustainability to it can reduce its risk correspondently, and the haze risk will be low. The number of lightning dangerous events will be relatively lower than the average, however, it is noticeable that the ChangAnJie road is a relative high lightning risk region. The possibility of fog will be relative high on the northern Yangqing and the southern Daxing district which lead to the moderate risk induced by fog. The low possibility of hot days and its good risk control and sustainability makes the low risk of high temperature
\end{abstract}

\section{Keywords}

Risk management; Risk assessment; Meteorological disasters; Risk analysis.

\section{大型活动期间雾霚灾害风险分析及风险 \\ 管理}

\author{
扈海波 ${ }^{1}$ 张艳莉 $^{2}$ \\ 1 中国气象局北京城市气象研究所, 北京 100089 , 中国 \\ 2 北京市气象局, 北京 100089 , 中国
}


摘要: 本文提出在风险识别及区划的基础上，通过风险承受与控制能力的分析，以大型活动 风险管理的模式实施雾䨪灾害风险评估，为活动的安全服务提供的决策依据。因此需要选用 层次分析模型并结合专家打分的方法，评估活动期间雾霧天气的风险承受与控制能力，依据 风险承受与控制能力对风险指数进行订正, 得到比较贴近真实风险状况的风险值, 据此进行 风险定级及排序。文章以北京地区 2015 年纪念抗战胜利阅兵活动期间气象灾害风险评估做 个例分析。针对霧雾有可能对活动造成的影响，在风险区划的基础上，完成风险评估及风险 承受与控制能力分析。评估发现䨪出现的概率很高, 风险承受与控制能力较好, 为低风险等 级。大雾在南部大兴和北部延庆一带出现概率较大, 风险为中等。

关键词：风险管理；风险评估；气象灾害

\section{1. 引言}

近年来国家经济快速发展，综合 国力不断提升。一些国内、国际大型 体育赛事、政治及文化等活动在我国 陆续召开。为保障这类活动的安全, 本着 “思则有备，备则无患” 的原 则, 气象部门陆续开展了针对这类活 动的气象灾害风险评估工作（扈海波 等 2009）。以北京为例，自 2008 年 来, 就相继完成了奥运、60 周年国 庆、世园会及 APEC 等活动期间的气 象灾害风险评估（扈海波等 2009）。 而在 2015 年也将对纪念抗战胜利阅兵 庆典活动期间的气象灾害风险进行评 估。风险评估要在这类活动的安全保 障工作中发挥重要作用, 除了要在风 险源调查的基础上进行风险识别和风 险分析, 重要的是要在评估的基础上 进行风险管理及风险处置 (Levy 2005; Tran et al. 2007; Chen et al. 2011; Klijn et al. 2012)。ISO 在 2009 年 11 月 颁布的风险管理国际标准中, 就指出 风险管理过程应当按照管理框架、风 险评价及风险处置三大步骤来实施, 而风险处置通常包括风险控制、风险 缓减、风险避免、风险转移、风险承 受等具体操作过程。针对大型活动的 风险评估的首要目的不仅仅是单纯作 风险区划, 另一个比较重要的工作是
需要评估活动能否承受这样的风险状 况, 这些风险能否得到有效控制, 从 而保障活动能安全顺利地进行。基于 风险管理的大型活动的风险评估的核 心工作是 “风险评价”与 “风险承受 与风险控制能力分析”，风险评价主 要是指风险源普查、风险识别及风险 分析等工作内容（扈海波等 2009 ; 扈 海波等 2013），而风险承受与控制能 力分析则更加贴近风险管理范畴 （Carre ńo et al. 2007）。居海波等 （2009）在 2008 年北京奥运会期间的 气象灾害风险评估的基础上提出了基 于 SAATY 方法的气象灾害风险承受能 力与风险控制能力的分析, 认为奥运 活动对高温和暴雨的风险承受与控制 能力最弱。这些为应急部门掌控活动 期间的风险源的风险状况提供依据， 为风险隐患的消除及风险防备提供决 策支持。

\section{2. 数据资料}

资料描述： 2000 年至 2014 年的北 京地区 20 个气候站的天气现象, 以及 由京津冀环境气象中心提供的 2000 年 以来评估期间的霾日统计结果。

提取的指标及用途:

(1)用能见度 $\leq 1 \mathrm{~km}$, 对应时刻的相 对湿度 $\geq 80 \%$ 的标准来统计雾日（扈海 波等 2010）。 
(2)霧日的判断标准是相对湿度 $\leq 80 \%$, 能见度 $\leq 10 \mathrm{~km}$, 其中 $P$ m 2.5

（扈海波等 2009）。

\section{3. 评估方法及过程}

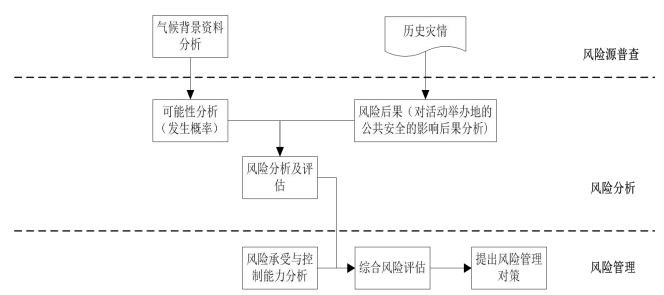

图 1: 气象灾害风险管理工作流程图

风险管理模式下活动期间的风险评 估工作流程是按照风险识别（风险源普 查）、风险分析、风险承受与控制能力 分析及综合风险评估来进行的。其中的 风险管理模块针对大型活动来设计及实 施的, 是一种狭义的风险管理模式。现 有关于风险管理的文献资料来看, 尽管 应用的目的各不相同, 但对风险管理的 理解却近乎一致。Carreńo 等 (2007) 从识别风险、减缓风险、灾害管理和政 策保护这四个方面, 建立风险管理的运 作模式。Tran 等 (2007) 把风险管理过 程细分为风险识别、风险评估及风险处 置三个阶段, 认为风险评估除了要考虑 可能性因素外, 还应注重经济、环境、 社会等的风险影响后果。大型活动的风 险评估至少应该包含风险源普查、风险 分析及风险管理三个阶段（图 1）。风 险源普查需要根据气候资料及历史灾 情, 得出活动举办期间有那些不利的天 气条件, 这些不利天气条件发生后会产 生什么样的风险后果。风险分析则是依 据这些不利天气的发生情况及风险后 果, 评估风险。风险管理则是依据这些 不利天气条件的所形成的风险状况, 分 析能否承受住不利天气条件所带来的风 险, 能否采取有效措施去控制风险及减 缓风险。

\section{1. 气象灾害风险分析过程}

大型活动的气象灾害风险采用 “风险=可能性 $*$ 风险后果”的方法 （Smith 1996）。实际操作时, 可采用 英国气象局沿用至今的风险矩阵法。 风险矩阵针对二维指标评估风险, 其 排列及组织原则是可能性越大及风险 后果等级越高, 风险就越大, 反之则 小。

个例统计北京地区 2000 年以来的 霧及雾在活动期间 (8月 30 日至 9 月 7 日，共十天）的发生概率，分析其发生 可能性。借助历史灾损资料对这种高影 响天气可导致的风险后果进行分级。实 际操作时则参考历史灾情并结合专家评 判的方法确定各气象灾害的风险后果 （严重性）等级。同时, 根据高影响天 气的发生频率 (日概率) 做可能性定 级。最后, 依据各高影响天气在评估期 间的可能性及风险后果, 用风险矩阵法 判断风险等级。

\section{2. 风险承受与控制能力分析}

气象灾害风险评估及风险管理多 采用层次分析模型进行风险承受与控 制能力分析评估(Levy 2005; 扈海波等 2009)。因此, 本文针对活动期间有可 能出现的高影响天气（大雾、雽）, 选取六项指标作风险承受能力与风险 控制能力分析。这六项指标为：(1)对 人口的影响; (2)对经济的影响; (3)对 阅兵活动的影响; (4) 预测预警能力; (5)人工影响自然灾害的能力; (6)规避 措施。前三项为风险承受能力指标, 指标(3)是为保障活动的安全而特设立 的指标, 后三项为风险控制能力指 标。上述指标归一化处理后, 用层次 分析模型评估风险承受与控制能力 （扈海波等 2008）。

通过层次分析模型, 可得到承受 与控制能力指标的权重向量 $W$, 结合承 
受与控制能力评估指标 $X$, 计算风险承 受与控制能力指数 $S$,

$$
S=\sum_{j=1}^{m} W(j) \cdot X(j)
$$

$m$ 为指标数。

表 1 北京地区阅兵期间气象灾害风险承受能力 与风险控制能力分析

\begin{tabular}{|c|c|c|c|c|c|c|c|c|c|}
\hline \multirow{2}{*}{$\begin{array}{l}\text { 项 } \\
\text { 目 } \\
\text { 灾和 }\end{array}$} & \multicolumn{9}{|c|}{ 风险承受能力指标 } \\
\hline & \multicolumn{3}{|c|}{$\begin{array}{c}\text { (3)阅兵活 } \\
\text { 动 }(\mathrm{S} 1=0.3)\end{array}$} & \multicolumn{3}{|c|}{$\begin{array}{c}\text { (1)人口 } \\
\text { (S2=0.15) }\end{array}$} & \multicolumn{3}{|c|}{$\begin{array}{c}\text { (2)经济 } \\
\text { (S3 }=0.15)\end{array}$} \\
\hline 等级 & 弱 & $\begin{array}{l}\text { 中 } \\
\text { 等 }\end{array}$ & 强 & 弱 & $\begin{array}{l}\text { 中 } \\
\text { 等 }\end{array}$ & 强 & 弱 & $\begin{array}{l}\text { 中 } \\
\text { 等 }\end{array}$ & 强 \\
\hline $\begin{array}{l}\text { 等级 } \\
\text { 值 }\end{array}$ & $\begin{array}{l}1 \\
- \\
3\end{array}$ & $\begin{array}{l}4 \\
- \\
6\end{array}$ & 7 & 1 & $\begin{array}{l}4 \\
-\end{array}$ & 7 & $\begin{array}{l}1 \\
- \\
3\end{array}$ & $\begin{array}{l}4 \\
- \\
6\end{array}$ & $\begin{array}{l}7 \\
-\end{array}$ \\
\hline 需 & \multicolumn{3}{|c|}{2} & \multicolumn{3}{|c|}{6} & \multicolumn{3}{|c|}{8} \\
\hline 大雾 & \multicolumn{3}{|c|}{3} & \multicolumn{3}{|c|}{6} & \multicolumn{3}{|c|}{5} \\
\hline
\end{tabular}

续表:

\begin{tabular}{|c|c|c|c|c|c|c|c|c|c|}
\hline \multicolumn{9}{|c|}{ 风险控制能力指标 } & \\
\hline \multicolumn{3}{|c|}{$\begin{array}{c}\text { (4)预测预警 } \\
\text { 能力 } \\
\text { (S4=0.15) }\end{array}$} & \multicolumn{3}{|c|}{$\begin{array}{l}\text { (5)人工影响 } \\
\text { 天气能力 } \\
\text { (S5=0.1) }\end{array}$} & \multicolumn{3}{|c|}{$\begin{array}{c}\text { (6)规避能力 } \\
(\mathrm{S} 6=0.15)\end{array}$} & \\
\hline 弱 & $\begin{array}{l}\text { 中 } \\
\text { 等 }\end{array}$ & 强 & 弱 & $\begin{array}{l}\text { 中 } \\
\text { 等 }\end{array}$ & 强 & 弱 & $\begin{array}{l}\text { 中 } \\
\text { 等 }\end{array}$ & 强 & \\
\hline $\begin{array}{l}1- \\
3\end{array}$ & $\begin{array}{c}4- \\
6\end{array}$ & $\begin{array}{c}7- \\
9\end{array}$ & $\begin{array}{l}1- \\
3\end{array}$ & $\begin{array}{l}4- \\
6\end{array}$ & $\begin{array}{c}7- \\
9\end{array}$ & $\begin{array}{l}1- \\
3\end{array}$ & $\begin{array}{l}4- \\
6\end{array}$ & $\begin{array}{c}7- \\
9\end{array}$ & \\
\hline \multicolumn{3}{|c|}{6} & \multicolumn{3}{|c|}{0} & \multicolumn{3}{|c|}{4} & 4.20 \\
\hline \multicolumn{3}{|c|}{5} & \multicolumn{3}{|c|}{0} & \multicolumn{3}{|c|}{2} & 3.60 \\
\hline
\end{tabular}

对于风险承受能力指标, 采用 Delphi 法多轮质询下的专家打分 (扈海 波等 2008), 将其分为影响大、影响中 和影响小三级, 并对各级赋予 2、5 和 8 值; 值越大, 表示风险的承受能力越 强。对后 3 项风险控制能力指标也分 为 3 级, 并对各级赋予 $8 、 5$ 和 2 值; 值越小, 表示风险控制能力越弱。最 后计算其总的得分作为风险系数, 分 数值越高, 表示风险的承受与控制能 力越强。其中 (1)-6系风险控制与承 受能力指标 $\left(S_{1}, S_{2}, S_{3}, S_{4}, S_{5}, S_{6}\right)$, 由层 次分析模型推算出的权重向量 $W$ 为
( 0.3 ,
0.15 ,
0.15 ,
$0.15,0.1$,

0.15 ）。这样风险承受与控制能力指 数 $S$ 的计算为

$$
\begin{gathered}
S=0.3 \times S_{1}+0.15 \times S_{2}+ \\
0.15 \times S_{3}+0.15 \times S_{4}+ \\
0.1 \times S_{5}+0.15 \times S_{6}
\end{gathered}
$$

风险承受能力与风险控制能力的 值越高其风险承受与控制能力越强。 利用上述方法的风险承受与控制能力 分析结果见表 1 。其中, 霧的风险承受 与控制能力最好。䨪的风险承受能力 和控制能力较好, 一般针对霧有一定 的控制及规避能力, 它对活动, 以及 人口和经济的影响相对较弱。

\section{4. 结果讨论}

近年来雾皬天气出现越来越频 繁, 也越加严重。这种天气给公众健 康安全带来极大的威胁, 重度䨪天气 还一度给公众带来相当的恐慌。霧的 发生与城市大气环境污染相关, “是 否有霾”已成为公众直观判断空气质 量的标准。通过统计, 发现近年来霾 天气在活动期间是一种经常出现的高 影响天气。䨪在活动期间的平均日出 现概率在 $19 \%$ 左右, 城区附近的霧日出 现概率相对较高, 在 $22 \%$ 左右。霾可能 性等级为 $\mathrm{A}$ 级, 其 $\mathrm{R}$ 值为 5 , 为中等风 险。䨝的风险承受与控制能力较高。 例如，在 2014 年北京 APEC 会议期 间, 空气质量整体变好, 以至习总书 记发出 “我希望并相信通过不解的努 力, APEC 蓝能够坚持下去” 的感叹。 所以通过风险承受与控制能力的订正 后, 霧的风险指数从 5 降低到 4.8 , 成 为低风险等级。

\section{5. 总结}


大型活动气象灾害风险评估在风 险分析的基础上实施风险风险承受与 控制能力分析, 为此类活动的安全提 供决策依据。风险评估首先在风险源 普查的基础上根据历史气候资料分析 活动期间高影响天气的发生可能性, 再依据不同高影响天气的风险后果判 别风险指数。 $\mathrm{R}$ 指数的判定可采用风险 矩阵的技术方法。为了实施有效的风 险管理, 本文提出了基于层次分析法 结合专家打分的方法, 分析活动期间 高影响天气 (霧及大雾) 的风险承受 与控制能力。风险承受能力涉及 “(1) 对人口的影响、(2)对经济的影响、(3) 对阅兵活动的影响” 的承受能力; 风 险控制能力则为 “ (4)预测预警能力、

(5)人工影响自然灾害的能力、(6)规避 措施” 的能力。通过对不同高影响天 气的风险承受与控制能力分析, 再对 各高影响天气的风险指数按照承受与 控制能力的大小进行指数订正, 这样 得到的风险指数大小才比较贴近于真 实的风险状况并对大型活动的安全服 务保障起指导作用。

\section{参考文献}

[1] 扈海波, 熊亚军, 董鹏捷, 轩春 怡.北京奥运期间(6-9月)气象灾害 风险评估.气象出版社, 2009 .

[2] Levy, J. K., 2005: Multiple criteria decision making and decision support systems for flood risk management. Stoch Environ Res Risk Assess, 19: 438-447.

[3] Tran, P., F. Marincioni, R. Shaw, et al., 2008: Flood risk management in Central Viet Nam: challenges and potentials Nat Hazards, 46:119-138. DOI 10.1007/s11069-007-9186-2.

[4] Chen, Y., C. Yeh, and B. Yu, 2011: Integrated application of the analytic hierarchy process and the geographic information system for flood risk assessment and flood plain management in Taiwan. Nat Hazards, 59:12611276.DOI10.1007/s11069-0119831-7.

[5] Chen, C. W., and C. P. Tseng, 2012: Default risk-based probabilistic decision model for risk. Nat Hazards, 63:659-671. DOI 10.1007/s11069012-0183-8.

[6] Klijn, F., J. M. Knoop, W. Ligtvoet, and M. J. P. Mens, 2012: In search of robust flood risk management alternatives for the Netherlands. Nat. Hazards Earth Syst. Sci., 12: 14691479.doi:10.5194/nhess-12-14692012.

[7] www.iso.org.rm/Risk management, GUIDE 73.

[8] 扈海波,轩春怡,诸立尚.北京地区城 市暴雨积涝灾害风险预评估. 应用 气象学报,2013,24(1): 99-108.

[9] Carreńo, M. L., O. D. Cardona, and A. H. Barbat,2007: A disaster risk management performance index. Nat Hazards , 41:1-20. DOI 10.1007/s11069-006-9008-y.

[10] Smith K. Environmental Hazards: Assessing Risk and Reducing Disaster (2nd edition). New York: Routledge, 1996.

[11] 黄崇福.自然灾害风险评价理论与 实践.,科学出版社, 2005.

[12] Kaplan, S., and B. J. Garrick, 1981: On The Quantitative Definition of Risk. Risk Analysis, 1(1): 11-27

[13] .扈海波,熊亚军,张姝丽.基于城市 交通脆弱性核算的大雾灾害风险 评估. 应用气象报, 2010,21(6):732738.

[14] ] 谢璞.中国气象灾害大典北京卷. 气象出版社, 2004.

[15] 扈海波, 王迎春, 熊亚军. 基于层次 分析模型的北京雷电灾害风险评 估. 自然灾害学报, 2010,19(1): 104-109. 